\title{
AN UNUSUAL CAUSE OF INTRAOPERATIVE HIGH AIRWAY PRESSURE AND VENTILATOR FAILURE: MESSAGE TO BE LEARNED
}

\author{
Anil Shrestha ${ }^{1}$, Bashu Dev Parajuli ${ }^{1, *}$, Pradip Tiwari ${ }^{1}$, Trishant Limbu ${ }^{1}$
}

${ }^{1}$ Department of Anaesthesiology, Institute of Medicine, Maharajgunj, Kathmandu, Nepal

\begin{abstract}
Received: 2 Oct, 2019
Accepted: 7 Mar, 2020

Published: 13 Mar, 2020

Key words: Airway pressure; Anesthesia ventilator; Anesthetic gas scavenging system; Malfunction.

*Correspondence to: Bashu Dev Parajuli, Department of Anaesthesiology, Institute of Medicine, Maharajgunj, Kathmandu, Nepal.

Email: bashuparajuli2012@gmail.com

DOI:https://doi.org/10.3126/jcmc.v10i1.28079

Citation

Shrestha A, Parajuli BD, Tiwari P, Limbu T. An unusual cause of intraoperative high airway pressure and ventilator failure: message to be learned.Journal of Chitwan Medical College.2020;10(31):82-84.

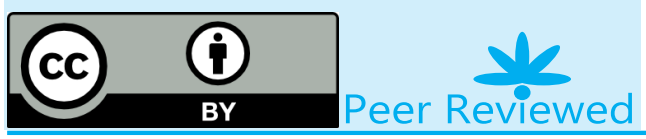

\section{INTRODUCTION}

The safety of conduction of anaesthesia depends upon the proper functioning of the anaesthesia equipment. With the malfunction of the anaesthesia equipment, the morbidity and mortality of patient increases. Anaesthesia machine malfunction is one of the most common cause of equipment related morbidity in anaesthesia. ${ }^{1}$ There are various problems reported related with anaesthesia machine. Most common encountered is that of breathing circuit. However, malfunctions of respiratory valve, power button, vaporizer, bellows and gas scavenging system have also been reported. ${ }^{1,2}$ The safety of patient should be ensured by both automated and manual checking of ventilator prior initiation of anaesthesia. ${ }^{3}$ Here, we have experienced one unusual cause of blockage of gas scavenging system in anaesthetized patient.
\end{abstract}

\section{CASE REPORT}

A 32 years old male, ASA physical status I patient, with diagnosis of Balanitis xerotica (BXO) with urethral structure with history of urethral dilation done 5 months back was undergoing urethroplasty with buccal mucosa graft under general an- esthesia with endotracheal intubation. The machine Mindray WATO EX- 35 was checked before the patient was brought to the operation room. The machine demonstrated no problem and passed the entire checklist.

The patient was brought to the operating room and regulator monitors were attached. Patient was anesthetised and manually ventilated until nasal intubation with size $6.5 \mathrm{~mm}$ flexometallic tube was done and switched to ventilator after confirmation of correct tube placement. The ventilator worked normally but after 7-8 breaths the peak pressure started to rise and alarm of sustained airway pressure activated and finally the ventilator stopped. Manual ventilation by same machine was done without any problem. Tubes, circuits, valves were checked and was found to have no problem. Patient was connected to ventilator and ventilated mechanically again but the same problem arose. The patient, tubes, circuits and machine including sodalime container were checked once again but no problem was found. Same fate was encountered again when the ventilator was used. We thought of changing the ventilator but suddenly our eye fell on a lead apron hanging on the back of the machine (Figure 1). Once the lead apron was removed from the machine the ventilator worked properly (Figure 2). It was found that someone had hanged a lead apron on the 
back of the machine which was obstructing the anesthetic gas scavenging system hence blocking the outflow of the machine causing back pressure.

This was one of the unusual causes of malfunction of the ventilator that we encountered, which was reported to department critical incident recording system.

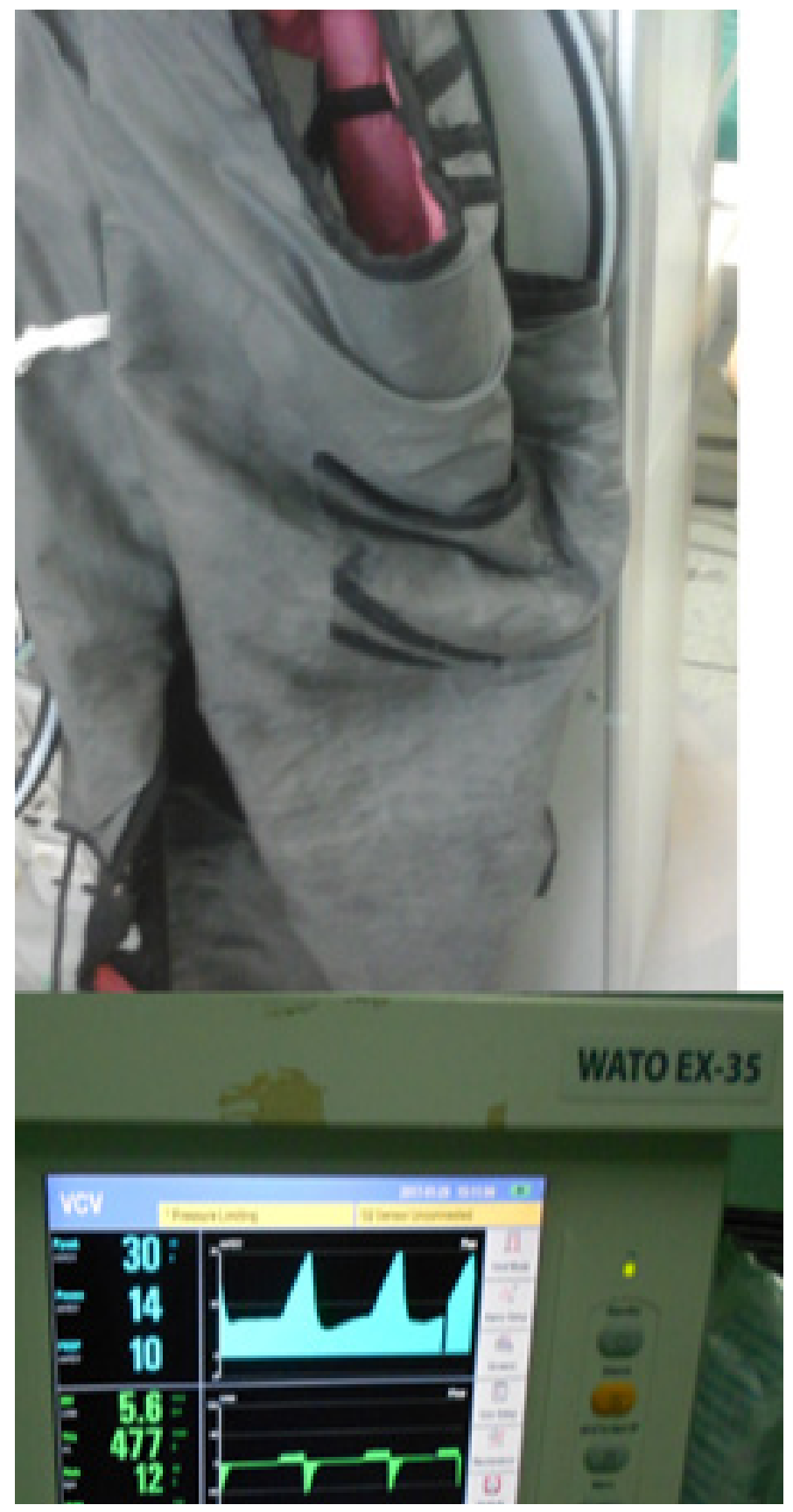

Figure 1: Lead apron covering exhaust valve causing increase of peak airway pressure.

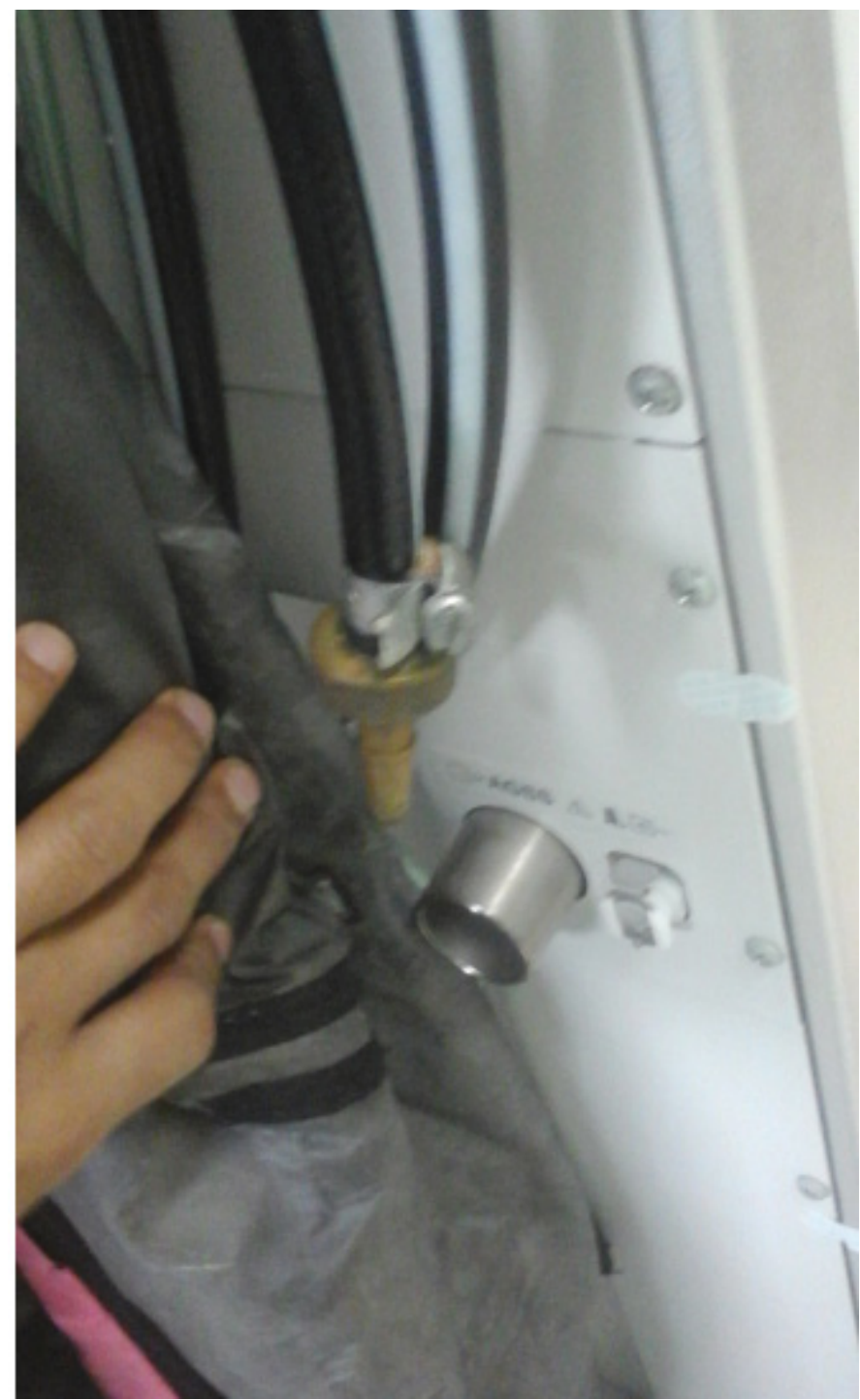

Figure 2: Exhaust Valve after removal of Lead apron.

\section{DISCUSSION}

Intraoperative problem is defined as "the event that requires one or more measures, either to prevent further complications or to treat a situation that is currently or potentially serious, and doesnot routinely occur during the conduction of anaesthesia." The problem can be graded according to the severity. Severity 'Grade 1' is a trivial problem, 'Grade 2' is a moderately difficult problem, with some effect on the patient, but of a low severity. 'Grade 3' is a serious situation that either proves very difficult to handle or causes a serious deterioration in the patient's state, which may or may not contribute to postoperative morbidity. 'Grade 4' problems are associated with a fatal outcome. The incidence and severity of problems can be affected by the anaesthesiologist's vigilance, preparation, anticipation and management skill. ${ }^{2}$

Intraoperative problems can be due to machine/equipment/s malfunction, human errors or patient related factors. The anaesthesia machine malfunction has been the commonest cause of equipment related morbidity and mortality. The breathing circuit problem has been identified the most common cause in 
many reports. Currently, the malfunction incidence has been decreasing due to availability of high yield ventilator with facilities of self-testing. ${ }^{2}$

There can be various causes of rise of airway pressure in the intraoperative period. ${ }^{4-7}$ We should always start checking form the patient chest, tube, circuit, valves or the exhaust system. In our case, once there was high pressure alarm during the controlled breath, we first switched to manually bag and mask ventilation to rule out causes related to chest, tube, circuit and valves. Once there was no problem identified, we switched to ventilator mode for controlled breaths. Soon after 6-8 breaths, there was alarm of high airway pressure. Thus, we looked distally to the expiratory valve i.e. sodalime canister and exhaust valve. We found the lead apron covering the opening of exhaust valve. This was the unusual cause of obstructing the exhaust valve which was detected in the initial minutes, thus the severity grade was trivial. This is an unusual example of shortcoming of relying only automatic check test by the ventilator as reported in a letter to editor by Joyal JJ et al. ${ }^{4}$

Thus there should be a systematic approach for intraoperative high airway pressure. We should always begin right from the patient's chest to endotracheal tube to breathing circuit or valves then to soda lime canister then to exhaust valve.

Thus anaesthesiologist should ensure the safety of patient by following the instructions proposed by ASA in 2008 and one should always consider, the auto checked ventilator can be malfunctioned any time in the intraoperative period. ${ }^{3}$ Besides, intraoperative vigilance, preparation and skill of tackling the problem of the attending anaesthesiologist would alter the incidence and severity grades of the problems. Finally, once any intra-operative problem is encountered then there should be system of reporting the critical incident recording system and they should be frequently analyzed. Lastly, the lead apron should be placed in a correct place to avoid unidentified mishaps.

\section{REFERENCES:}

1. Copper JB, Newbower R, Kitz RJ. An analysis of major errors and equipment failure in anesthesia management: considerations for prevention and detection. Anaesthesiology 1984;60:34-42. [DOI]

2. Fasting S, Gisvold SE. Equipment problems during anaesthesia-are they a quality problem?. Br J Anaesth 2002;89:825-31. [DOI]

3. American Society of Anaesthesiologists (ASA). Guidelines for designing pre-anaesthesia checkout procedures (2008). [LINK]

4. Joyal JJ, Vannucci A, Kangrga I. High End-Expiratory Airway Pressures Caused by Internal Obstruction of the Draeger Apollo Scavenger System
That Is Not Detected by the Workstation Self-test and Visual Inspection Anesthesiology 2012;116:1152-66. [DOI]

5. Desai S, Torgal S, Rao R. Breathing circuit obstruction caused by kink in the reinforced kink-resistant circle system tube. Indian J Anaesth. 2013;57:96-7. [DOI]

6. Yang $\mathrm{CH}$, Chen $\mathrm{KH}$, Lee $\mathrm{YE}$, Lin $\mathrm{CR}$. Anaesthetic breathing circuit obstruction mimicking severe bronchospasm: An unusual manufacturing defect. Acta Anaesthesiol Taiwan. 2012;50:35-7. [DOI]

7. Vinay B, Sriganesh K, Gopalakrishna KN, Sudhir V. An unusual cause of high peak airway pressure: Interpretation of displayed alarms. Saudi J Anaesth. 2015 Jan;9(1):94-6. [DOI] 